\title{
Phosphoproteome of the Oleaginous Green Alga, Chlorella vulgaris UTEX 395, under Nitrogen-Replete and -Deplete Conditions
}

\author{
Michael T. Guarnieri' ${ }^{1 *}$, Alida T. Gerritsen ${ }^{2}$, Calvin A. Henard ${ }^{1}$ and Eric P. Knoshaug ${ }^{1}$ \\ ${ }^{1}$ National Bioenergy Center, National Renewable Energy Laboratory, Golden, CO, United States, ${ }^{2}$ Computational Science \\ Center, National Renewable Energy Laboratory, Golden, CO, United States
}

Keywords: microalgae, biofuels, phosphoproteome, lipids, Chlorella vulgaris

The unicellular green alga, Chlorella vulgaris UTEX 395, represents a promising biocatalyst for renewable biofuel production due to its relatively rapid growth rate and high lipid accumulation capacity (Guarnieri et al., 2011, 2012; Gerken et al., 2013; Griffiths et al., 2014; Zuniga et al., 2016). Prior analyses have unveiled the global proteome dynamics of C. vulgaris following nitrogen depletion, which induces a high lipid accumulation phenotype (Guarnieri et al., 2011, 2013). More recently, we have reported a draft genome, genome-scale model, and nitrosoproteome for this alga (Zuniga et al., 2016; Henard et al., 2017) ${ }^{1}$ providing further insight into lipid biosynthetic-, nutrient response-, and post-transcriptional-regulatory mechanisms. To further our understanding of these regulatory mechanisms and expand the knowledge base surrounding this organism, comparative phosphoproteomic analyses were conducted under nitrogen-replete and -deplete conditions to identify differentially phosphorylated proteins that will aid in the evaluation of the potential role of phosphoregulation in lipogenesis.

Xiamen University, China

Reviewed by:

Xianhai Zeng,

Yingchun Wang,

Chinese Academy of Sciences,

China

*Correspondence:

Michael T. Guarnieri

michael.guarnieri@nrel.gov

Specialty section:

This article was submitted to

Bioenergy and Biofuels,

a section of the journal

Frontiers in Bioengineering and

Biotechnology

Received: 04 October 2017

Accepted: 12 February 2018

Published: 06 March 2018

Citation:

Guarnieri MT, Gerritsen AT, Henard CA and Knoshaug EP (2018) Phosphoproteome of the Oleaginous

Green Alga, Chlorella vulgaris UTEX 395, under Nitrogen-Replete and - Deplete Conditions.

Front. Bioeng. Biotechnol. 6:19. doi: 10.3389/fbioe.2018.00019

\section{METHODS}

\section{Algal Cultivation}

Chlorella vulgaris UTEX 395 was cultivated in biological triplicate, as described previously (Guarnieri et al., 2011, 2013). Briefly, algae were inoculated at $\mathrm{OD}_{750}=0.05$ in $1 \mathrm{~L}$ Roux bottles using modified Bold's Basal Media (mBBM). Cultures were maintained at $25^{\circ} \mathrm{C} \pm 1^{\circ} \mathrm{C}$, with continuous $(24 \mathrm{hr}$ ) white fluorescent light illumination $\left(200 \mu \mathrm{E} \mathrm{m}^{-2} \mathrm{~s}^{-1}\right)$. Cultures were supplemented with $2 \% \mathrm{CO}_{2} /$ air and mixed with a magnetic stir bar at $500 \mathrm{rpm} .50 \mathrm{~mL}$ of nitrogen-replete cell culture was harvested at $\mathrm{OD}_{750}=2$, centrifuged for $5 \mathrm{~min}$ at $5,000 \times \mathrm{g}$, and immediately quenched on liquid nitrogen. To induce nitrogen deprivation, the remaining cell culture was centrifuged for $5 \mathrm{~min}$ at 5,000 $\times g$, washed once in nitrogen-free $\mathrm{mBBM}$, and resuspended in nitrogen-free $\mathrm{mBBM}$ for continued growth to $\mathrm{OD}_{750}=4$, followed by harvest, as described above. Cell pellets were immediately quenched in liquid nitrogen.

\section{Protein Isolation}

Cell pellets were thawed and solubilized on ice in $2 \mathrm{~mL}$ of lysis buffer [50 mM Tris, pH 8.0, $150 \mathrm{mM}$ $\mathrm{NaCl}, 1 \mathrm{mM}$ DTT, 10\% glycerol, supplemented with $1 \times$ PhosSTOP Phosphatase Inhibitor Cocktail (Roche Diagnostics Corporation)]. The cells were then sonicated on ice at $4^{\circ} \mathrm{C}$, at $90 \%$ power setting for $30 \mathrm{~s} \times 6$ cycles, with a $1 \mathrm{~min}$ cool-down period between sonication cycles using a Braun Sonic-L

${ }^{1}$ Guarnieri, M. T., Levering, J., Zengler, K., Henard, C. A., Boore, J. L., and Knoshaug, E. P. (under review). Genome sequence of the oleaginous green alga, Chlorella vulgaris UTEX 395. Submitted to Bioengineering and Biotechnology. 
ultrasonicator. Lysates were cleared via two cycles of centrifugation at $16,000 \times g$ at $4^{\circ} \mathrm{C}$ for $30 \mathrm{~min}$, and the supernatants were isolated for use in subsequent phosphoproteomic analysis.

\section{Peptide Digestion and Phosphopeptide Enrichment}

$500 \mu \mathrm{g}$ of lysate material was digested in solution with the following concentration of buffer and enzymes: $100 \mathrm{mM} \mathrm{DTT}, 20 \mathrm{mM}$ HEPES, $100 \mathrm{mM}$ iodoacetamide, $25 \mathrm{ng} / \mu \mathrm{L}$ trypsin (final E:S ratio of $1: 20$ ), and $20.5 \%$ TFA. $200 \mu \mathrm{g}$ of peptide were desalted using solid phase extraction on a Waters C18 Sep Pak 1cc cartridge (part no. WAT054960) as follows: column was activated with

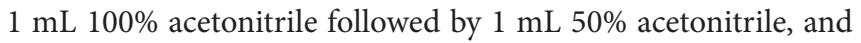
equilibrated with $3 \times 1 \mathrm{~mL} 0.1 \%$ TFA. The sample was loaded on column and washed $2 \times$ with $1 \mathrm{~mL} 0.1 \%$ TFA, followed by elution with $0.5 \mathrm{~mL} 60 \%$ acetonitrile, $0.1 \%$ TFA. The eluate was dried to completion and phosphopeptides were enriched using the GL Sciences TiO2 kit (5010-21312), following manufacturer's instructions. Samples were dried to completion and resuspended in $120 \mu \mathrm{L} 0.1 \%$ TFA.

\section{Phosphoproteomic Analysis}

Each enriched sample was analyzed by nano LC/MS/MS with a Waters NanoAcquity HPLC system interfaced to a ThermoFisher $\mathrm{Q}$ Exactive. The acquisition order was randomized. In each case, peptides were loaded on a trapping column and eluted over a $75 \mu \mathrm{m}$ analytical column at $350 \mathrm{~nL} / \mathrm{min}$; both columns were packed with Jupiter Proteo resin (Phenomenex), employing a $2 \mathrm{~h}$ gradient, as follows: buffer $\mathrm{A}-0.1 \%$ formic acid in water; buffer $\mathrm{B}-0.1 \%$ formic acid in acetonitrile; $\mathrm{t} 0=2 \% \mathrm{~B}, \mathrm{t} 1 \mathrm{~min}=5 \% \mathrm{~B}, \mathrm{t} 95=25 \%$ $\mathrm{B}, \mathrm{t} 110=35 \% \mathrm{~B}, \mathrm{t} 112=90 \% \mathrm{~B}, \mathrm{t} 113=2 \% \mathrm{~B}, \mathrm{t} 120=2 \% \mathrm{~B}$. The mass spectrometer was operated in data-dependent mode, with MS performed in the Orbitrap at 70,000 FWHM resolutions and MS/MS performed using HCD and product ions detected in the Orbitrap at 17,500 FWHM resolutions. The 15 most abundant ions were selected for MS/MS.

\section{Data Processing}

Data were processed through the MaxQuant software v1.5.1.0 (www.maxquant.org) for MS data recalibration, database filtering to $1 \%$ false discovery rate (FDR), calculation of peak areas (label-free), and assignment of phosphosite localization probability. Data were searched using a local copy of Andromeda with the following parameters: (i) Enzyme: trypsin/P, (ii) Database:

\section{REFERENCES}

Gerken, H. G., Donohoe, B., and Knoshaug, E. P. (2013). Enzymatic cell wall degradation of Chlorella vulgaris and other microalgae for biofuels production. Planta 237, 239-253. doi:10.1007/s00425-012-1765-0

Griffiths, M. J., van Hille, R. P., and Harrison, S. T. L. (2014). The effect of nitrogen limitation on lipid productivity and cell composition in Chlorella vulgaris. Appl. Microbiol. Biotechnol. 98, 2345-2356. doi:10.1007/s00253-013-5442-4

Guarnieri, M. T., Laruens, L. M. L., Knoshaug, E. P., Chou, Y. C., Donohoe, B. S., and Pienkos, P. T. (2012). Complex Systems Engineering: A Case Study for an Unsequenced Microalga. Hoboken, NJ: John Wiley \& Sons, Inc.

Guarnieri, M. T., Nag, A., Smolinski, S. L., Darzins, A., Seibert, M., and Pienkos, P. T. (2011). Examination of triacylglycerol biosynthetic pathways via de novo
Cv395_Maker_7100 (concatenated forward and reverse plus common contaminants), (iii) Fixed modification: carbamidomethyl (C), (iv) Variable modifications: oxidation (M), acetyl (protein $\mathrm{N}$-term), phospho (STY), (v) fragment mass tolerance: $20 \mathrm{ppm}$. The Phospho(STY)Sites output was further processed using Excel. A total of 691 phosphosites (considering positional variances within the same peptide) were detected at 1\% FDR.

\section{Data Analysis}

All analysis of intensities utilized the R language (r-project.org). Proteins with no blastx identification were removed from the analysis. Intensities were filtered for presence in two of three replicates to remove erroneous measures and then compared for strict presence/absence in the two conditions. The filtered dataset of raw intensities was then analyzed for differential expression using the edgeR package (Robinson et al., 2010) and the top differentially expressed genes $(p<0.05)$ were analyzed further for gene ontology $(\mathrm{GO})$. GO identifications for each protein were obtained in tab-separated format from the UniProt web interface (uniprot.org) and parsed in R to compare the top GO terms in the control replete cells versus the depleted cells. GO terms were split into molecular function, cellular component, and biological process categories when comparing between the treatments.

\section{Phosphoproteome Data Deposition}

A master file with the full list of phosphosites and associated localization and statistical data is deposited at the FigShare repository, along with differential expression and GO analyses. All files are accessible at: https://figshare.com/s/f870b1fc4c9896f4ef81.

\section{AUTHOR CONTRIBUTIONS}

Project planning and wet lab execution were conducted by EK and MG. AG and $\mathrm{CH}$ directed phosphoproteome data processing and handling. MG and AG wrote the manuscript.

\section{ACKNOWLEDGMENTS}

This work was supported by National Renewable Energy Laboratory, Laboratory-Directed Research and Development grants 06511103 and 06511301, and the U.S. Department of Energy, Office of Energy Efficiency and Renewable Energy under Agreement No. 22000. We kindly thank Drs. Richard Jones and David Allen for assistance in phosphoproteomic data acquisition.

transcriptomic and proteomic analyses in an unsequenced microalga. PLoS ONE 6:e25851. doi:10.1371/journal.pone.0025851

Guarnieri, M. T., Nag, A., Yang, S., and Pienkos, P. T. (2013). Proteomic analysis of Chlorella vulgaris: potential targets for enhanced lipid accumulation. J. Proteomics 93, 245-253. doi:10.1016/j.jprot.2013.05.025

Henard, C. A., Guarnieri, M. T., and Knoshaug, E. P. (2017). The Chlorella vulgaris S-nitrosoproteome under nitrogen-replete and -deplete conditions. Front Bioeng Biotechnol 17:100. doi:10.3389/fbioe.2016.00100

Robinson, M. D., McCarthy, D. J., and Smyth, G. K. (2010). edgeR: a bioconductor package for differential expression analysis of digital gene expression data. Bioinformatics 26, 139-140. doi:10.1093/bioinformatics/btp616

Zuniga, C., Li, C. T., Huelsman, T., Levering, J., Zielinski, D. C., McConnell, B. O., et al. (2016). Genome-scale metabolic model for the green alga Chlorella vulgaris 
UTEX395 accurately predicts phenotypes under autotrophic, heterotrophic, and mixotrophic growth conditions. Plant Physiol 172, 589-602. doi:10.1104/ pp.16.00593

Disclaimer: The views and opinions of the authors expressed herein do not necessarily state or reflect those of the United States Government or any agency thereof. Neither the United States Government nor any agency thereof, nor any of their employees, makes any warranty, expressed or implied, or assumes any legal liability or responsibility for the accuracy, completeness, or usefulness of any information, apparatus, product, or process disclosed, or represents that its use would not infringe privately owned rights.
Conflict of Interest Statement: The authors declare that the research was conducted in the absence of any commercial or financial relationships that could be construed as a potential conflict of interest.

Copyright $\odot 2018$ Guarnieri, Gerritsen, Henard and Knoshaug. This is an openaccess article distributed under the terms of the Creative Commons Attribution License (CC BY). The use, distribution or reproduction in other forums is permitted, provided the original author(s) and the copyright owner are credited and that the original publication in this journal is cited, in accordance with accepted academic practice. No use, distribution or reproduction is permitted which does not comply with these terms. 